\title{
Inactivated tetanus as an immunological smokescreen; a major step towards harnessing tetanus-based therapeutics.
}

\author{
Thomas McLean ${ }^{1}$, Luke Norbury ${ }^{1}$, Russell Conduit ${ }^{1}$, Natalie Shepherd ${ }^{1}$, Peter Coloe ${ }^{1}$, \\ Anthony Sasse $^{2}$, and Peter Smooker ${ }^{1}$ \\ ${ }^{1}$ RMIT University \\ ${ }^{2}$ Latrobe Regional Hospital, Gippsland, Australia
}

May 14, 2020

\begin{abstract}
Background and Purpose: Tetanus neurotoxin has many potential therapeutic applications, due to its ability to increase localised muscle tone when injected directly into a muscle. It is a closely related molecule to botulinum neurotoxin (most commonly known as Botox), which has been widely used to release muscle tension for therapeutic and cosmetic applications. However, tetanus toxin has been relegated to the "maybe pile" for protein therapeutics - as most of the population is vaccinated, leading to highly effective antibody-mediated protection against the toxin. The potential for tetanus-based therapeutics remains substantial if the problem of pre-existing immunity can be resolved. Experimental Approach: A well-established murine model of localised muscular contraction was utilised. We administered functional tetanus toxin combined with an immunogenic, but functionally inactive, decoy molecule. Key Results: Incorporation of the decoy molecule greatly reduces the dose of active toxin required to induce a localised increase in muscle tone in mice vaccinated with the human toxoid vaccine. Conclusion and Implications: Our results clearly demonstrate that the barriers to developing a tetanus toxin therapeutic are not insurmountable and the technology presented here is the first major step towards realising the therapeutic potential of this powerful neurotoxin. Opening the therapeutic potential of tetanus toxin will have huge implication for the wide range of diseases caused by low-tone muscle.
\end{abstract}

\section{Background and Purpose:}

Tetanus neurotoxin has many potential therapeutic applications, due to its ability to increase localised muscle tone when injected directly into a muscle. It is a closely related molecule to botulinum neurotoxin (most commonly known as Botox), which has been widely used to release muscle tension for therapeutic and cosmetic applications. However, tetanus toxin has been relegated to the "maybe pile" for protein therapeutics - as most of the population is vaccinated, leading to highly effective antibody-mediated protection against the toxin. The potential for tetanus-based therapeutics remains substantial if the problem of pre-existing immunity can be resolved.

Experimental Approach: A well-established murine model of localised muscular contraction was utilised. We administered functional tetanus toxin combined with an immunogenic, but functionally inactive, decoy molecule.

Key Results: Incorporation of the decoy molecule greatly reduces the dose of active toxin required to induce a localised increase in muscle tone in mice vaccinated with the human toxoid vaccine.

\section{Conclusion and Implications:}

Our results clearly demonstrate that the barriers to developing a tetanus toxin therapeutic are not insurmountable and the technology presented here is the first major step towards realising the therapeutic 
potential of this powerful neurotoxin. Opening the therapeutic potential of tetanus toxin will have huge implication for the wide range of diseases caused by low-tone muscle.

Keywords: Tetanus toxin, muscle tone, sleep apnoea, protein therapeutic, immune evasion, immunological smokescreen, skeletal muscle

\section{Introduction}

Tetanus neurotoxin (TeNT) is the only known molecule that can sustainably increase the neurological tone of skeletal muscle localised to the point of injection. It is one of a family of Clostridial neurotoxins that can modulate muscle function. The therapeutic potential of Botulinum neurotoxin (BoNT; available commercially as Botox ${ }^{\mathrm{TM}}$, Dysport ${ }^{\mathrm{TM}}$, Xeomin ${ }^{\mathrm{TM}}$ or Myobloc $^{\mathrm{TM}}$ ) has long been realised; however, not so for TeNT. BoNT has been used extensively for more than 25 years as a therapeutic treatment for a myriad of diseases caused by muscle disorders (Chen, 2012, Dressler, 2012, Johnson, 1999, Patil et al. , 2016). It has also found widespread use as a cosmetic agent (Monheit and Pickett, 2017). As BoNT acts by relaxing skeletal muscle, it can theoretically be applied locally to any skeletal muscle, and possibly smooth muscle, and the range of diseases that can be treated is broadening. According to Dressler (2016), usage is split approximately evenly between therapeutic and cosmetic applications (Dressler, 2016).

BoNT has seven known serotypes, A to G, with type A and B being licensed for human use (Patil et al. , 2016). They are derived fromClostridium botulinum, Clostridium butyricum andClostridium barati and are the most potent toxins found in nature (Poulain and Popoff, 2019). Together with TeNT (derived fromClostridium tetanii ) they comprise the family of clostridial neurotoxins. Although structurally and functionally related, BoNTs and TeNT have quite different effects on muscle, with BoNTs causing flaccid paralysis and TeNT spastic paralysis (Connan and Popoff, 2017). This is because BoNTs act on the motor neurones, directly inhibiting them, while TeNT is retrogradely transported up the motor neuron to the central nervous system (CNS), where it inhibits transmitter release in inhibitory neurones. This has the effect of reducing inhibition of motor neuron firing, resulting in greater neurological muscle signalling, leading to greater tone and eventually contraction.

This begs the question: Why is TeNT not being used as a therapeutic in a similar manner to BoNT, given that there are many diseases that could benefit from increasing muscle tone. TeNT is a candidate for treating obstructive sleep apnoea (OSA) and spinal cord injury after proof-of-principle was established in dog studies (Hesse et al. , 2020, Conduit et al. , 2007, Sasse et al. , 2005). Some other candidates for such treatments are motor neuron disease, neuropathies, myelopathies and myopathies involving decreased motor neuron output, pelvic floor muscular disorders, and disorders regarding muscular sphincter tone. The greatest barrier to the use of TeNT is widespread vaccination with tetanus toxoid, particularly in developed countries where coverage rates can exceed $90 \%$ (Seither et al. , 2019). In immune individuals it is expected that low doses of TeNT, equivalent to those used for BoNT therapy, would be ineffective. In a model using mice either passively or actively immunised against the toxin, local tetany could only be induced with over 10,000 times the dose required in naïve animals (Fishman et al. , 2009). These levels are lethal in non-immunised mice.

For human use, a reduction in the amount of administered toxin to the lowest possible level while still retaining activity is vital. This means that neutralising antibody activity towards the toxin must be minimised or effectively bypassed. We have chosen to do this by providing an excess of immunogenic but non-functional toxin to act as a "smokescreen" to minimise the effectiveness of antibodies locally. We show that this dramatically reduces the active dose required in a mouse model. This opens the way for development of TeNT as a human therapeutic.

\section{Methods}

\section{Designation of TeNT Domains}

The designation of TeNT domain sequences was based on previously reported sequences: TTc (Umland et al. , 1997), Light-chain (Eiselet al. , 1993), and TeNT (Eisel et al. , 1986b). TeNT comprises 1314 amino 
acids (the full protein without the N-terminal methionine residue (Studier, 2005)), TTc comprises amino acids 864-1314 of TeNT, LCHn comprises amino acids 1-863 of TeNT.

Expression vector construction

In silico gene design and codon optimisation for expression of TeNT in E. coli B strains was performed using Genome Compiler (http://www.genomecompiler.com/, Twist Bioscience). The TeNT gene was synthesised with 3' Xho I and 5' Hind III endonuclease sites by IDT (Sydney, Australia). The gene was digested from the pUCIDT delivery vector by combining $1 \mu \mathrm{g}$ of plasmid DNA with 20 units of Xho I (NEB) and 20 units of Hind III (NEB) in $1 \times$ cutsmart buffer (NEB) and incubating for $1 \mathrm{~h}$ at $37^{\circ} \mathrm{C}$. One microgram of target vector (pRSET-A; ThermoScientific) was digested in the same manner. Digested DNA was separated on a gel red (Biotium) stained $1 \%$ agarose gel for $1.5 \mathrm{~h}$ at $70 \mathrm{~V}$. DNA was visualised on a transilluminator blue light box and the bands corresponding to the TeNT gene and pRSET-A vector were excised and DNA extracted from the gel using Bioline's gel extraction kit (Bioline). TeNT gene insert and pRSET-A vector at a molar ratio of $3: 1$, respectively, were combined in $1 \times \mathrm{T} 4$ ligase buffer $(\mathrm{NEB})$. One unit of T4 ligase was added and ligation was allowed for $16 \mathrm{~h}$ at $16^{\circ} \mathrm{C}$. One microlitre of ligation reaction was used to transform electrocompetent E. coli D10 $\beta$ cells (NEB). Plasmid DNA from colonies on the selection plates was extracted by miniprep (Bioline) and digested with Xho I and Hind III as previously outlined. Digested products were analysed by separation on a $1.5 \%$ agarose gel for $1.5 \mathrm{~h}$ at $70 \mathrm{~V}$. The gene construct was designated as pRSET-TeNT.

The tetanus toxin light-chain/translocation domain ( $\mathrm{LCHn}$ ) gene was codon optimized for E. coli expression and synthesised with added 5'Xho I and 3' Hind III endonuclease sites to facilitate sub-cloning into the pRSET-A expression vector (Thermofisher). The LCHn gene was sub-cloned into pRSET-A by digestion with Xho I andHind III followed by ligation (performed by Genscript, U.S.A.). The vector was designated pRSET-LCHn.

The x-ray crystallography-derived, three-dimensional structure of the TTc sub-domain of tetanus toxin (PDB 1AF9 (Umland et al. , 1997)) was visualised using discovery studio (Biovia, v1.7). To prevent or reduce the receptor binding capability of TTc, amino acid residue mutations R1225E and W1288A situated in the receptor binding pockets of TTc were selected and introduced to the sequence. The TTc R1225E W1288A gene was then codon optimized, synthesised with 5' Xho I and 3'Hind III endonuclease sites and sub-cloned into pRSET-A as already outlined. The gene construct was designated pRSET-TTc R1225E W1288A.

\section{Protein expression}

The TeNT and decoy proteins were expressed individually in E. coli BL21(DE3) $\mathrm{p} L y s$ S, using a customised high-optical density expression protocol (adapted from (Studier, 2005)). In brief, 100 nanograms of the corresponding vector was used to electrotransformE. coli BL21 (DE3) $\mathrm{p} L y s \mathrm{~S}$ cells. The expression host was grown in liquid media with selection antibiotics then transferred to expression media where protein expression was induced by the addition of IPTG.

\section{Purification of TeNT}

Recombinant TeNT was purified by $\mathrm{NiSO}_{4}$ IMAC followed by size-exclusion chromatography (SEC) on an AKTApure 25 FPLC system (GEHealthcare). Briefly, post-expression, cells were pelleted at $4500 \times \mathrm{g}$ for $15 \mathrm{~m}$. Cell pellets were either stored at $-80^{\circ} \mathrm{C}$ or immediately sonicated on ice in IMAC buffer $(50 \mathrm{mM}$ Tris, $300 \mathrm{mM} \mathrm{NaCl}, \mathrm{pH}$ 8). Post-sonication cell lysate was cleared by centrifugation at 4,500 $\times \mathrm{g}$ for $15-30 \mathrm{~m}$ at $4^{\circ} \mathrm{C}$ and the supernatant filtered through a $0.45 \mu \mathrm{m}$ membrane filter (Whatman). The sample, supplemented with $20 \mathrm{mM}$ imidazole, was then applied to a $1 \mathrm{~mL}$ high purity Histrap $\mathrm{NiSO}_{4}$ column (GEHealthcare) at $1 \mathrm{ml} / \mathrm{min}$. The sample was washed and eluted with IMAC buffer supplemented with $20 \mathrm{mM}$ and $300 \mathrm{mM}$ imidazole, respectively. The eluted sample was concentrated, and buffer exchanged to phosphate buffered saline (PBS) using a Vivaspin20 column (50 kDa MWCO; Sartorious) as described by the manufacturer. Five hundred microlitres of sample was then applied to a Superdex 200 increase 10/300 size exclusion column (GEHealthcare) and eluted in PBS.

Purification of decoy proteins 
The recombinant decoy proteins (TTc R1225E W1288A and LCHn) were purified individually by $\mathrm{NiSO}_{4}$ IMAC as outlined above, with the exception that $1 \mathrm{~mL}$, gravity fed NTI-sepharose columns (Thermofisher) were used. Additionally, $0.5 \mathrm{mM}$ CHAPS was incorporated into the sample buffer and an additional column wash incorporating $0.5 \mathrm{mM}$ CHAPS was added. Wash and elution buffers included $20 \mathrm{mM}$ and $300 \mathrm{mM}$ imidazole, respectively. Post-IMAC purification the samples were concentrated, and buffer exchanged into PBS using Vivaspin20 columns (30 kDa or 50 kDa MWCO; Sartorious).

\section{TeNT activation}

TeNT was activated by cleavage with trypsin to produce the di-chain form, where the light- and heavychains are linked only by a disulfide bond. One milligram of purified TeNT was incubated with $200 \mu \mathrm{L}$ of immobilised TPCK trypsin (Thermofisher) in $0.1 \mathrm{M} \mathrm{NH}_{4} \mathrm{HCO}_{3}$, $\mathrm{pH} 8$ at $37^{\circ} \mathrm{C}$ for three hours as outlined in the manufacturer's protocol. Immobilised trypsin was separated by centrifugation. Completeness of cleavage was confirmed by SDS-PAGE.

\section{SDS-PAGE}

Proteins were separated by one-dimensional SDS-PAGE using 4-15\% TGX precast gels (Biorad) at $180 \mathrm{~V}$ for $45 \mathrm{~min}$. Prior to gel loading, samples were incubated at $95^{\circ} \mathrm{C}$ for $3 \mathrm{~min}$ in loading buffer containing $\beta$-mercaptoethanol for reducing gels, or loading buffer without a reducing agent at $75^{\circ} \mathrm{C}$ for $10 \mathrm{~m}$ for nonreducing gels. Pre-stained Kaleidoscope ${ }^{\mathrm{TM}}$ protein standard, or Precision Plus Protein Dual Colour Standard (Biorad) were used as markers if immunotransfer was subsequently undertaken, while unstained Precision Plus Protein (Biorad) standard was used for gels that were to be stained by Coomassie blue.

\section{Coomassie staining}

After electrophoresis, gels were submerged in Coomassie blue stain for 1-3 h. Gels were destained for $1 \mathrm{~h}$ in a solution of $40 \%$ methanol and $10 \%$ acetic acid then destained for a further $1-3 \mathrm{~h}$ in a solution of $20 \%$ methanol and 10\% acetic acid. Following destaining, the gels were stored in $10 \%$ acetic acid.

\section{Immunotransfer \& Immunoblotting}

Immunotransfer was undertaken using an iblot system (Invitrogen) with nitrocellulose membranes according to manufacturer's protocol. The nitrocellulose membrane was blocked with blocking buffer (5\% Skim milk powder in Tris-buffered saline (TBS)) for $1 \mathrm{~h}$. All incubations and washes were performed on a rotating shaker. The membrane was washed twice in TBS for $2 \mathrm{~min}$, and then the primary antibody (Rabbit antiTeNT IgG, ab53829, Abcam) diluted to 1:10,000 in blocking buffer was added for $2 \mathrm{~h}$ at room temperature (or overnight at $4 \mathrm{oC}$ ). The blot was washed twice in TBS for $5 \mathrm{~min}$, and the secondary antibody (Goat anti-rabbit IgG conjugated with AP, ab6722, Abcam) diluted to 1:10,000 in blocking buffer was added and incubated at room temperature for up to $2 \mathrm{~h}$. The blot was washed three times in TBS $0.05 \%$ tween for 5 min. To develop the AP conjugate, the blot was immersed in Western Blue ${ }^{\mathrm{TM}}$ (Promega) solution for 5-10 min. until the desired resolution was achieved. The blot was washed in $\mathrm{dH} 2 \mathrm{O}$ to stop the reaction.

\section{Endotoxin removal/LAL assay}

Endotoxin was removed from all proteins using Endotoxin removal columns (Pierce, Thermoscientific) as per the manufacturer's protocol. Briefly, 4-6 $\mathrm{mg}$ of protein diluted to $2 \mathrm{ml}$ in PBS buffer was incubated in a prepared column at room temperature for 6 hours or at $4 \mathrm{degC}$ for 18 hours prior to elution. The procedure was repeated four times consecutively for each protein with the columns regenerated in between. Endotoxin levels were determined by LAL assay (Pierce, Thermoscientific) following the manufacturer's instructions. Chromogenic readings at OD $405 \mathrm{~nm}$ were taken using a Clariostar plus plate reader (BMG Labtech).

\section{Determining protein concentration}

The extinction coefficient of the proteins was determined from the protein sequence using the Protparam tool from Expasy (https://web.expasy.org/protparam/). The concentration was determined by absorbance 
at $280 \mathrm{~nm}$ using a Nanodrop One (Thermo Scientific). The final concentration was determined by the value obtained from the absorbance divided by the value predicted by the extinction coefficient of a $0.1 \%$ solution.

Animal trials

All animal procedures were performed in accordance with protocols approved by the Animal Ethics committee of the Royal Melbourne Institute of Technology (RMIT) University, Melbourne. All protocols adhere to the Victorian Prevention of Cruelty to Animals Act 1986, the associated Regulations (2008), and the Australian Code for the Care and Use of Animals for Scientific Purposes (2013) (the 'Animal Code') and the Australian Code for the Responsible Conduct of Research 2018.

Mice were randomised, after being deemed to have generated antibody to tetanus toxin. Blinded observations were not deemed necessary- a progressive scheme for the progression of tetany was followed (see below).

The local effects of tetanus toxin and decoy solutions were determined by injecting toxin solutions directly into the gastrocnemius muscle of one hind limb of female, C57BL6 mice. In brief, the TeNT and/or decoy proteins were diluted to the desired concentration in PBS in a total volume of 15-25 $\mu \mathrm{L}$. Mice were anaesthetised individually by isofluorane inhalation and injected with the solution using a 27-gauge tuberculin syringe. The mice were monitored consistently at $1-4 \mathrm{~h}$ intervals for symptoms of localised tetany based on a modified motor behavior scale reported by Webster and Laurence, 1963 (Laurence and Webster, 1963). Stage $1=$ limb tetanus that involved only part of limb, stage $2=$ limb tetanus consistently evoked on attempted limb movement and usually involving the entire limb, stage $3=$ intermittent spontaneous limb tetanus, and stage $4=$ sustained localized limb tetanus. The trial endpoint was considered when the mice reached either stage 4 , or 48 hours post-injection, whichever occurred first. The group size was $\mathrm{n}=6$ per dose for vaccinated animals and $n=3$ per dose for non-vaccinated animals. Group sizes were determined based on pilot studies to analyse variations based on individual susceptibility to TeNT and variance in titres of anti-TeNT antibodies in vaccinated animals.

To induce anti-tetanus immunity, 4-week-old mice were vaccinated three times with human divalent diphtheria - tetanus vaccine (ADT, Sequiris) at a dose of $2 \mathrm{IU}$ of tetanus toxoid at 3-week intervals

Serum collection

Blood was collected from the saphenous vein 3 weeks post the final vaccination from each animal. After 1 $\mathrm{h}$ at room temperature blood was spun at $1500 \times \mathrm{g}$ for $10 \mathrm{~min}$ and serum collected. A random pool of 12 mice were bled prior to vaccination to obtain serum controls.

\section{Serum ELISA}

The TeNT-specific antibody titre of each vaccinated animal was determined in triplicate by serum ELISA. In brief, 96 well plates were coated overnight with $0.5 \mu \mathrm{g}$ of recombinant TeNT in carbonate coating buffer $\mathrm{pH}$ 9.6. Plates were washed three times with PBS $0.05 \%$ tween and blocked with PBS $5 \%$ skim milk for $1 \mathrm{~h}$ at $37^{\circ} \mathrm{C}$. Plates were washed three times with PBS $0.05 \%$ tween then coated with serial dilutions, in triplicate, of the mouse serum in PBS 1\% skim milk, starting at an appropriate concentration for each sample determined by a pilot ELISA. Each plate also had an internal control sample, derived from a pool of sera determined to be suitable from the pilot ELISA. Plates were incubated for $1 \mathrm{~h}$ at $37^{\circ} \mathrm{C}$ then washed three times with PBS $0.05 \%$ tween. Wells were coated with $100 \mu \mathrm{L}$ of Goat anti-mouse IgG HRP conjugated antibodies (A4416 Sigma) diluted to 1:5000 in PBS $1 \%$ skim milk and incubated for $1 \mathrm{~h}$ at $37^{\circ} \mathrm{C}$. The plates were washed three times with PBS $0.05 \%$ tween, developed with TMB Chromogenic solution (Invitrogen.) in the dark for 10-30 minutes, then stopped with $1 \mathrm{M} \mathrm{HCl}$, according to the manufacturer's protocol. Absorbance at 450 $\mathrm{nm}$ was determined using a Clariostar plus plate reader (BMG Labtech). Sample titres were calculated as the antibody dilution that gave half the maximum OD (as determined from the internal standards in each plate at a 1:16,000 dilution) and calculated using GraphPad Prism (version 8.3).

Data analysis/statistics 
Data was analysed using GraphPad Prism (version 8.3). For determination of significance, multiple t-test analyses were performed to compare groups at individual time-points or individual doses.

\section{Materials (others indicated above)}

Xho I and Hind III; NEB

pRSET-A; ThermoScientific

E. coli D10ß cells; NEB

Histrap $\mathrm{NiSO}_{4}$ column; GEHealthcare

Vivaspin20 column, 50 kDa MWCO; Sartorious

Rabbit anti-TeNT IgG, ab53829; Abcam

Superdex 200 increase 10/300 size exclusion column; GEHealthcare

Divalent diphtheria - tetanus vaccine (ADT); Sequiris

\section{Results}

Study design and protein preparation

Active TeNT and decoy TTc R1225E W1288A and LCHn were expressed from the pRSET vector constructs in E. coli BL21 (DE3). The decoy molecules comprised the binding domain of tetanus toxin (TTc) with two point-mutations to prevent neuronal binding and a separately produced enzymatic-translocation domain (LCHn). The mutations introduced in TTc were reported to be involved in neuronal binding (Sutton et al. , 2001, Bakry et al. , 1991, Chen et al. , 2009, Ovespianet al. , 2015, Qazi et al. , 2006), and LCHn was inactive due to the peptide bond between the light-chain (LC) and Hn domain and absence of a binding domain (TTc) (Figure 1A, B and C). The overall flow of the animal experiments is represented schematically in figure $1 \mathrm{D}$, and an example of tetany stage observations is shown in figure $1 \mathrm{E}$.

TeNT and decoy proteins were produced in milligram amounts, per litre of culture, at purity levels estimated to be greater than 95\% (Figures 2A, B and C). Post-purification, full-length TeNT was cleaved into its active di-chain form by treatment with TPCK-trypsin. The activated protein, when analysed by SDS-PAGE, showed the expected pattern of separate $100 \mathrm{kDa}$ and $50 \mathrm{kDa}$ protein subunits representing the heavy and light chains of the toxin, respectively (Figure 2A). The presence of several different sizes of light-chain is expected due to slight variations in cleavage by trypsin. This has been reported previously and does not appear to affect the activity of the protein (Ahnert-Hilger et al. , 1990, KRIEGLSTEIN et al. , 1991). The presence of the disulphide bond between the heavy- and light-chains, required for the biological activity of the toxin, was confirmed by comparing the protein on reducing and non-reducing SDS-PAGE (Figure 2A). The presence of a single $150 \mathrm{kDa}$ protein on the non-reducing gel confirmed the presence of the disulphide bond. Even though E. coli BL21 is reported to have a reducing cytosol, the protein was produced with an oxidised disulfide bond. Whether the bond was formed during protein folding withing the cell, or spontaneously during the purification or activation process is unknown. Identity of the proteins were confirmed by Western blot using primary antibodies derived against tetanus toxoid (Rabbit anti-TeNT IgG). Polyclonal antibodies recognised both the TTc and LCHn components of the decoy (Figure 2B and C), suggesting that both subunits are targeted by the immune response. This is consistent with studies investigating TeNT immunity (da Silva Antunes et al. , 2017, Lavinder et al. , 2014, Palermo et al. , 2017).

Mouse vaccination and titre confirmation

To obtain consistently high anti-TeNT antibody titres, mice were vaccinated three times, at three-week intervals with 2 tetanus toxoid international units of human divalent diphtheria-tetanus vaccine (ADT, Seqirus). Immunity of the mice was confirmed by injecting a small subset of animals with 500 times the TeNT dose capable of inducing stage 4 tetany in naïve mice within 24 hours; no symptoms of tetanus were observed. The titres of all mice data included in the study were confirmed to be protective $(>1: 8000$ 
(Fishman et al. , 2009)) by serum ELISA, three weeks following the final vaccination. Data for mice with non-protective titres $(<1: 8,000$, three mice) were excluded from the study and where appropriate the group size was changed from $\mathrm{n}=6$ to $\mathrm{n}=5$ (Supplementary data Table 1 ).

Induction of tetany in naïve mice

The rate of tetany symptom development and the stage of tetany reached was dose dependent. At doses of $0.01 \mathrm{ng}$ of TeNT or greater, stage 4 tetany was reached for all naive mice (Figure $3 \mathrm{~A}-\mathrm{C}$ ). Some variation in the time taken for symptoms to develop was typically reported in both vaccinated and non-vaccinated mice. Decoy administered to naïve mice, at a $100 \mu \mathrm{g}$ equimolar dose, did not induce any symptoms, confirming the decoy is unable to induce tetany. TeNT administered at doses of $0.01 \mathrm{ng}, 0.1 \mathrm{ng}$ and $1 \mathrm{ng}$, in combination with $100 \mu \mathrm{g}$ of decoy, were considerably less effective than TeNT administered alone (Figure 3A, B and C). This would suggest an inhibitory effect of the decoy, possibly due to residual binding activity of the TTc R1225E W1288A component preventing neuronal binding of the active toxin, either by flooding receptors or through steric hinderance.

Induction of tetany in vaccinated mice

The minimum dose of TeNT where tetany was detected in vaccinated mice was $250 \mathrm{ng}$, with one third of mice observed with stage one tetany within 48 hours (Figure $4 \mathrm{~A}$ and B). At a $500 \mathrm{ng}$ dose, half of the mice exhibited stage one tetany symptoms within 48 hours. Half of the mice reached stage 4 tetany by 48 hours with $1 \mu \mathrm{g}$ and $2 \mu \mathrm{g}$ TeNT doses, and all mice reached stage 4 tetany in 24 hours with a dose of $4 \mu \mathrm{g}$ (Figures $4 \mathrm{~A}$ and $\mathrm{B}$ ), with symptoms developing more rapidly at greater doses. These results broadly concur with previous studies of native TeNT administered to vaccinated mice (Fishman et al. , 2009). When administered with $100 \mu \mathrm{g}$ of decoy, a TeNT dose of $500 \mathrm{ng}$ induced stage 4 tetany in all mice by 24 hours (Figures $4 \mathrm{~A}$ and C). This suggests an activity similar to $4 \mu \mathrm{g}$ of TeNT alone, an 8-fold increase in activity in vaccinated mice. The lowest dose tested, $0.2 \mathrm{ng}$ TeNT with $100 \mu \mathrm{g}$ of equimolar decoy solution, induced stage 1 tetany in two thirds of mice, greater than the effect shown when $250 \mathrm{ng}$ of TeNT was administered alone (Figures 4A, B and $\mathrm{C}$ ). A direct comparison of the time course of tetany development in mice administered $500 \mathrm{ng}$ and 250 ng of TeNT, with and without $100 \mu \mathrm{g}$ of equimolar decoy solution, demonstrated a significant increase in activity of the decoy-accompanied treatment, with greater tetany stages exhibited in a shorter time (Figures $4 \mathrm{D}$ and $\mathrm{E}$ ). Together, these data demonstrated that the decoy effectively improved the activity of TeNT and that the effect is more pronounced at lower toxin concentrations. Furthermore, the increase between a minimal observable effect dose and the dose required to induce stage four tetany in under 24 hours was considerably greater with the decoy present.

The effect of decoy concentration on TeNT activity in vaccinated mice

In vaccinated mice, reducing the concentration of decoy, while maintaining the concentration of active TeNT, showed a trend of reduced TeNT activity (Figure $5 \mathrm{~A}-\mathrm{D}$ ). As we have demonstrated that the decoy has an inhibitory effect on TeNT activity in naïve mice, there is likely a concentration dependent balance between the positive effect of diverting antibodies and TeNT inhibition by the decoy. Unlike when combined with 100 $\mu \mathrm{g}$ of decoy, at $20 \mu \mathrm{g}$ and $5 \mu \mathrm{g}$ of decoy, $500 \mathrm{ng}$ of TeNT was not enough to induce stage 4 tetany in all mice. Further, $5 \mu \mathrm{g}$ of decoy combined with $25 \mathrm{ng}$ of TeNT was slightly less effective than $5 \mathrm{ng}$ of TeNT with $100 \mu \mathrm{g}$ of decoy (Figures 5B and D). Comparison of the time-course of tetany development demonstrated that there was a significant difference in the effectiveness of the decoy depending on its concentration. Interestingly, development of TeNT symptoms at $100 \mu \mathrm{g}$ and $20 \mu \mathrm{g}$ of decoy were not significantly different at $0.01 \mathrm{ng}$ and $0.1 \mathrm{ng}$ doses of TeNT, while TeNT showed less activity in the presence of $5 \mu \mathrm{g}$ of decoy at these doses (Figures 5C and D). While at a $1 \mathrm{ng}$ dose of TeNT, activity was significantly higher in combination with $100 \mu \mathrm{g}$ of decoy compared to either $20 \mu \mathrm{g}$ or $5 \mu \mathrm{g}$ of decoy (Figure $5 \mathrm{D}$ ).

Statistical analysis

Multiple t-test analyses were applied to each group of mice at each time point to determine the statistical significance of the results. On graphs displaying three or more data sets, multiple t-tests were performed 
between each pair or data. Many data points were determined to be significant $(\mathrm{p}<0.05)$ by this method, denoted by the asterisks on the graphs (Figures 3, 4 and 5). However, this analysis is an imperfect application as the values obtained from our observations are not arithmetically related. The statistical analysis assumes that a value of 4 is twice a value of 2 , for example, which does not match our data as our values are based on scoring physiological symptoms, and are therefore, semi-quantitative. Multiple t-tests were applied as a best-fit scenario, but a lack of statistical significance does not mean the results are not showing real variation.

\section{Discussion}

We demonstrated a significant improvement in the efficacy of TeNT in vaccinated mice when administered alongside an inactivated decoy toxin. We propose that the decoy is acting as an immunological smokescreen, binding to protective antibodies, thus preventing them from neutralising some of the active TeNT. The is similar to a method of invasion employed by some bacteria and parasites (Wilson et al. , 2003). This effectively is analogous to reducing the concentration of circulating TeNT-neutralising antibodies. Furthermore, the decoy molecules were shown to be inert, retaining no residual, tetany-inducing activity. This is, to our knowledge, the first report of directly improving the activity of a tetanus toxin dose in vaccinated animals. The greatest increases in activity were observed at lower doses of TeNT. When TeNT was administered alone to vaccinated animals, we observed symptoms of tetany started at a dose of $250 \mathrm{ng}$ with all mice reaching the trial endpoint at a dose of $4 \mu \mathrm{g}$. When administered alongside $100 \mu \mathrm{g}$ of equimolar decoy solution, we observed symptoms at doses of TeNT as low as $0.2 \mathrm{ng}$, with a gradual increase in the responses observed as TeNT doses were increased to $250 \mathrm{ng}$, with all mice reaching the trial endpoint at a dose of $500 \mathrm{ng}$. TeNT administered alone exhibited a dose range of 16 -fold from first detectable symptoms to all animals reaching the trial endpoint. This range increased to 2,500-fold when TeNT was administered with $100 \mu \mathrm{g}$ of decoy molecules. These results suggest, that when combined with the decoy molecules, the effective activity of TeNT was greatly improved, and the likelihood of overdose was greatly reduced.

Tetanus toxin could be a tremendously impactful biological therapeutic for the treatment of neuromuscular disorders. It could revolutionise the treatment of disorders such as OSA (affecting approximately $5 \%$ of the population with significant health and economic burdens (Benjafieldet al. , 2019)), and spinal cord injury, and additionally has cosmetic and veterinary applications (Conduit et al. , 2007, Sasseet al. , 2005, Hesse et al. , 2020). Furthermore, the TTc domain has great potential as a non-disruptive mechanism for drug delivery across the barriers associated with the CNS (Benn et al. , 2005, Figueiredo et al. , 1997, Fishman et al. , 1990, Francis et al. , 2004, Moreno-Igoa et al. , 2010). The therapeutic and cosmetic success of botulinum toxin demonstrates how powerful a substance that can control muscle tone can be (Patil et al. , 2016, Pirazzini et al. , 2017, Shapira and Benhar, 2010, Dressler, 2012).

Human vaccination against tetanus introduces challenges to the successful development of therapeutic tetanus toxin. Protective immunity is induced by vaccination with tetanus toxoid, an inactivated form of tetanus toxin, which leads to a highly effective and long-lasting, antibody mediated response, directed against the toxin, rendering low-doses ineffective. The effect of the vaccination is long-lasting with a reported 14-year serum half-life of circulating antibodies (Borella-Venturini et al. , 2017, Mayer et al. , 2002). BoNT has been successfully applied as a therapeutic and cosmetic, because although it is the most potent neurotoxin known, it can be used safely in extremely low doses, to induce a mild, localised response (Chen, 2012, Dressler, 2012, Johnson, 1999). Overdoses can occur, but these result in paralysis of the local muscle group rather than a systemic issue (Taban and Perry, 2006). With careful administration, TeNT could be safely used to control local muscle tone, when the opposite effect to Botox is required - at least in a non-vaccinated individual.

Vaccination rates against Tetanus are high, but not complete. This must be considered when approaching tetanus toxin therapeutics, as a non-vaccinated person, or non-responder to vaccination, would be far more susceptible to the toxin than someone with a highly effective immune response. In 2009, Fishman et. al. demonstrated that localised tetany could be induced in a vaccinated population of mice (Fishman et al. , 2009). However, there was a relatively narrow dosage window between non-response and severe signs of tetany, and significant variability between individual animals; possibly caused by variability in serum antibody titre. Although the induction of a localised response in vaccinated animals was promising, the 
study demonstrated the need for a more sophisticated approach.

There has been significant study undertaken on the molecular characterisation of TeNT from the 1980s onwards; however, TeNT is a complicated molecule and the mechanics of its actions and interactions are still not completely understood (Gramlich et al. , 2013, Wanget al. , 2012, Pirazzini et al. , 2016, Rossetto et al. , 2011). In fact, an accurate structure of TeNT, derived from x-ray crystallography, was only solved in 2017 (Masuyer et al. , 2017). Tetanus toxin has a three sub-domain structure, split into two chains joined by a disulfide bond in the active form, very similar in structure and function to the botulinum toxins (Beise et al. , 1994, Eiselet al. , 1986a, Helting and Zwisler, 1977, Masuyer et al. , 2017, Masuyer et al. , 2011, Turton et al. , 2002). The main difference between tetanus and botulinum is that tetanus is transported to the CNS, where it disrupts the synaptic vesicle fusion complex in the inhibitory interneuron, thereby increasing the neurological signal to the corresponding muscle (Ovespian et al. , 2015, Lalli et al. , 2003, Bercsenyi et al. , 2013, Caleo and Schiavo, 2009, Restani et al. , 2012). Botulinum, conversely, acts in the peripheral nervous system to prevent the firing of the motor neuron synapse (Grumelli et al. , 2005, Lalli et al. , 2003, Patilet al. , 2016, Pirazzini et al. , 2017). It was therefore proposed that substitutions from botulinum to tetanus toxin, in regions other than that required for transport to the CNS, could yield a therapeutically viable version of the toxin with the activity of tetanus, but with reduced immunogenicity (Fürch et al., 2007, Wang et al. , 2008, Wang et al. , 2012). The results were surprising though as substitution of the enzymatic region of BoNT to TeNT (thought to be analogous) resulted in a TeNT with the activity of a BoNT (Wang et al. , 2012). Furthermore, recent studies characterising the human and murine antibody response to TeNT have demonstrated protective that antibodies recognise multiple epitopes in the binding, transport and enzymatic regions of the toxin (Palermoet al. , 2017, Lavinder et al., 2014, da Silva Antuneset al., 2017, Yousefi et al. , 2014, Lukić et al. , 2015, Qazi et al. ,2006). There is also significant variation in the immunodominant epitopes between individual humans, and although mouse antibodies tend to recognize similar regions to humans, the specific sequences recognised are different. This leads to the conclusion that selectively mutating immunogenic regions would be unlikely to give the same results in mice and humans (Yousefi et al. , 2016). Due to these difficulties, we have focused on developing "sequence agnostic" approaches to improving the therapeutic potential of tetanus toxin.

We predict the dose of TeNT required to treat a condition such as OSA, or other conditions, is significantly less than the dose required to induce an observable physiological response. There is evidence to support this assumption reported in the treatment of OSA symptoms in a British bulldog (Sasse et al. , 2005), and the treatment of spinal cord injury in dogs (Hesse et al. , 2020). For the purpose of this study we compared doses required to induce observable tetany in vaccinated animals, as we were demonstrating the effectiveness of our approach on avoiding immunity, rather than analysing models of disease. Certainly, the clinically relevant dose of toxin would be significantly smaller than that required to induce physically observable signs of localised tetany, and by extension, systemic tetany. The questions therefore remain, does the decoy approach improve TeNT activity enough to treat disease without risking any sort of dangerous response at the same dose in a vaccinated or non-vaccinated individual? If not, can a simple serum ELISA be used to predict the safe dose for an individual? To find answers, studies could be performed in an animal model of OSA such as the British bulldog, as demonstrated by Sasse et. al.(2005).

It is necessary to consider that the decoy solution may boost the antibody response itself - a common problem with protein therapeutics in general (Dressler, 2002, Benecke, 2012, Naumann et al. , 2013). However, TeNT is an unusual case when it comes to protein therapeutics. While with other proteins, avoidance of the induction of immunity is paramount, for TeNT, that immunity already exists. Furthermore, the fact that this methodology could be applied to any protein, would suggest that it may be useful when long-term administration of a protein therapeutic has produced immunity that renders it ineffective, for example with Botox (Albrecht et al. , 2019, Hefter et al. , 2019, Dressler, 2002, Benecke, 2012). The decoy doses applied here, $5-100 \mu \mathrm{g}$, are quite high, but the dose of active TeNT required would be extremely low compared to some other commonly used protein therapeutics, so the combined therapeutic dose of TeNT and decoy could be kept within reasonable margins. For example, adalimumab is administered at a $40 \mathrm{mg}$ dosage fortnightly for rheumatoid arthritis, plaque psoriasis, ankylosing spondylitis and Crohn's disease, 
while interferon $\beta 1$-a is administered at between 20 and $250 \mu \mathrm{g}$, either weekly or multiple times per week, for the treatment of multiple sclerosis (Naumann et al. , 2013). By contrast, we predict a TeNT therapeutic would be administered once every three to six months, at doses in the nanogram range: similar to Botox (Naumann et al. , 2013). The decoy solution tested was an equimolar solution of TTc R1225E W1288A and LCHn and was shown to have an inhibitory effect on TeNT activity in naïve mice. With further refinement, the inhibitory effect could be reduced or resolved, and the concentration of each component could be changed in such a way that the overall dose of decoy proteins required could be reduced.

TeNT has the potential to be a transformative protein therapeutic. Our results clearly demonstrate the potential of the decoy technology and support the idea that the barriers to developing a TeNT therapeutic are not insurmountable. Conditions that are either caused by low muscle tone or could be treated by increasing muscle tone, are numerous, often debilitating, and come with significant social and economic burdens. We believe that the technology presented here is the first major step towards realising the therapeutic potential of this powerful neurotoxin.

\section{Author Contributions}

TM contributed to conceptualization, project planning, experimental design, experimental execution, data analysis, manuscript drafting and manuscript editing.

LN contributed to conceptualization, project planning, experimental design, experimental execution, data analysis, manuscript drafting and manuscript editing.

RC contributed to conceptualization, project planning, experimental design, experimental execution, data analysis, funding acquisition, manuscript drafting and manuscript editing.

PC contributed to conceptualization, project planning, experimental design and funding acquisition.

NK contributed to conceptualization, project planning, experimental design and manuscript editing.

AS contributed to conceptualization, project planning, funding acquisition, and manuscript editing.

PS contributed to conceptualization, project planning, experimental design, experimental execution, data analysis, funding acquisition, manuscript drafting and manuscript editing.

\section{Acknowledgements}

The work was supported by an Australian Research Council linkage grant, [LP100200710] for PS, PC, RC and AS and an RMIT ECP development grant [EOF 17079] for PS, PC, RC and AS.

The authors thank the RMIT Animal Facility staff for assistance, and Julie Zilko for proofreading.

References

AHnERT-Hilger, G., DAUZENROth, M. E., HABERMAnN, E., HENSCHEN, A., KRIEGLSTEIN, K., MAULER, F. \& WELLER, U. 1990. Chains and fragments of tetanus toxin, and their contribution to toxicity. Journal de Physiologie, 84, 229-236.

ALBRECHT, P., JANSEN, A., LEE, J.-I., MOLL, M., RINGELSTEIN, M., ROSENTHAL, D., BIGALKE, H., et al. 2019. High prevalence of neutralizing antibodies after long-term botulinum neurotoxin therapy.Neurology, 92, e48-e54.

BAKRY, N., KAMATA, Y., SORENSEN, R. \& SIMPSON, L. L. 1991. Tetanus toxin and neuronal membranes: the relationship between binding and toxicity. Journal of Pharmacology and Experimental Therapeutics,258, 613-619.

BEISE, J., HAHNEN, J., ANDERSEN-BECKH, B. \& DREYER, F. 1994. Pore formation by tetanus toxin, its chain and fragments in neuronal membranes and evaluation of the underlying motifs in the structure of the toxin molecule. Naunyn-Schmiedeberg's Archives of Pharmacology, 349, 66-73. 
BENECKE, R. 2012. Clinical relevance of botulinum toxin immunogenicity.BioDrugs, 26, e1-e9.

BENJAFIELD, A. V., AYAS, N. T., EASTWOOD, P. R., HEINZER, R., IP, M. S., MORRELL, M. J., NUNEZ, C. M., et al. 2019. Estimation of the global prevalence and burden of obstructive sleep apnoea: a literature-based analysis. The Lancet Respiratory Medicine,7, 687-698.

BENN, S. C., AY, I., BASTIA, E., CHIAN, R.-J., CELIA, S. A., PEPINSKY, R. B., et al. 2005. Tetanus toxin fragment $\mathrm{C}$ fusion facilitates protein delivery to CNS neurons from cerebrospinal fluid in mice.Journal of Neurochemistry, 95, 1118-1131.

BERCSENYI, K., GIRIBALDI, F. \& SCHIAVO, G. 2013. The elusive compass of clostridial neurotoxins: Deciding when and where to go? Current Topics in Microbiology and Immunology.

BORElla-VEntURINI, M., FrASSON, C., PAluAN, F., DE NUZZO, D., DI MASI, G., GIRALDO, M., et al. . 2017. Tetanus vaccination, antibody persistence and decennial booster: a serosurvey of university students and at-risk workers. Epidemiology and Infection, 145,1757-1762.

CALEO, M. \& SCHIAVO, G. 2009. Central effects of tetanus and botulinum neurotoxins. Toxicon, 54, 593-599.

CHEN, C., FU, Z., KIM, J.-J. P., BARBIERI, J. T. \& BALDWIN, M. R. 2009. Gangliosides as High Affinity Receptors for Tetanus Neurotoxin. The Journal of Biological Chemistry, 284, 26569-26577.

CHEN, S. 2012. Clinical uses of botulinum neurotoxins: current indications, limitations and future developments. Toxins,4, 913-939.

CONDUIT, R., SASSE, A., HODGSON, W., TRINDER, J., VEASEY, S. \& TUCKER, A. 2007. A neurotoxinological approach to the treatment of obstructive sleep apnoea. Sleep Medicine Reviews, 11, 361-375.

CONNAN, C. \& POPOFF, M. R. 2017. Uptake of clostridial neurotoxins into cells and dissemination. Uptake and Trafficking of Protein Toxins. Springer.

DA SILVA ANTUNES, R., PAUL, S., SIDNEY, J., WEISKOPF, D., DAN, J. M., PHILLIPS, E., et al. 2017. Definition of human epitopes recognized in tetanus toxoid and development of an assay strategy to detect ex vivo tetanus CD4+ T cell responses. PloS one,12, e0169086.

DRESSLER, D. 2002. Clinical features of antibody-induced complete secondary failure of botulinum toxin therapy. European neurology,48, 26-29.

DRESSLER, D. 2012. Clinical applications of botulinum toxin. Current Opinion in Microbiology, 15, 325-336.

DRESSLER, D. 2016. Botulinum toxin drugs: brief history and outlook.Journal of Neural Transmission, $123,277-279$.

EISEL, U., JARAUSCH, W., GORETZKI, K., HENSCHEN, A., ENGELS, J., WELLER, U., et al. 1986a. Tetanus Toxin - Primary Structure, Expression in Escherichia-Coli, and Homology with Botulinum Toxins. Embo Journal, 5, 2495-2502.

EISEL, U., JARAUSCH, W., GORETZKI, K., HENSCHEN, A., ENGELS, J., WELLER, U., et al . 1986b. Tetanus toxin: primary structure, expression in E. coli, and homology with botulinum toxins. The EMBO journal,5, 2495-2502.

EISEL, U., REYNOLDS, K., RIDDICK, M., ZIMMER, A. \& NIEMANN, H. 1993. Tetanus toxin light chain expression in Sertoli cells of transgenic mice causes alterations of the actin cytoskeleton and disrupts spermatogenesis. The EMBO journal, 12, 3365-3372.

Figueiredo, D. M., HALlEWELl, R. A., CHEN, L. L., FAIRWEATHER, N. F., DOUGAN, G., SAVITT, J. M., et al . 1997. Delivery of recombinant tetanus-superoxide dismutase proteins to central nervous system neurons by retrograde axonal transport. Experimental Neurology,145, 546-554. 
FISHMAN, P. S., PARKS, D. A., BOWEN, T. \& MATTHEWS, C. C. 2009. Localized tetanus in immunized mice. Neurotoxicology,30, 697-701.

FISHMAN, P. S., SAVITT, J. M. \& FARRAND, D. A. 1990. Enhanced CNS uptake of systemically administered proteins through conjugation with tetanus C-fragment. Journal of the Neurological Sciences,98, 311-325.

FRANCIS, J., BASTIA, E., MATTHEWS, C., PARKS, D., SCHWARZSCHILD, M., BROWN, R. \& FISHMAN, P. 2004. Tetanus toxin fragment C as a vector to enhance delivery of proteins to the CNS. Brain research,1011, 7-13.

FÜRCH, T., WITTMANN, C., WANG, W., FRANCO-LARA, E., JAHN, D. \& DECKWER, W. D. 2007. Effect of different carbon sources on central metabolic fluxes and the recombinant production of a hydrolase from Thermobifida fusca in Bacillus megaterium. Journal of Biotechnology,132, 385-394.

GRAmlich, P. A., Remington, M. P., Amin, J., Betenbaugh, M. J. \& FiShman, P. S. 2013. Tat-tetanus toxin fragment C: A novel protein delivery vector and its use with photochemical internalization. Journal of Drug Targeting, 21, 662-674.

Grumelli, C., Verderio, C., POZzI, D., ROssetto, O., MONTECUCCO, C. \& MATteoli, M. 2005. Internalization and mechanism of action of clostridial toxins in neurons. Neurotoxicology, 26,761-767.

HEFTER, H., ROSENTHAL, D., BIGALKE, H. \& MOLL, M. 2019. Clinical relevance of neutralizing antibodies in botulinum toxin long-term treated still-responding patients with cervical dystonia. Therapeutic Advances in Neurological Disorders, 12,1756286419892078.

HELTING, T. B. \& ZWISLER, O. 1977. Structure of tetanus toxin. I. Breakdown of the toxin molecule and discrimination between polypeptide fragments. Journal of Biological Chemistry, 252,187-193.

HESSE, S., KUTSCHENKO, A., BRYL, B., DEUTSChlAnD, M. \& LIEBETANZ, D. 2020. Therapeutic effects of Tetanus neurotoxin in spinal cord injury: a case series on four dogs. Spinal Cord Series and Cases,6, $1-10$.

JOHNSON, E. A. 1999. Clostridial toxins as therapeutic agents: benefits of nature's most toxic proteins. Annu Rev Microbiol, 53,551-75.

KRIEGLSTEIN, K. G., HENSCHEN, A. H., WELLER, U. \& HABERMANN, E. 1991. Limited proteolysis of tetanus toxin: relation to activity and identification of cleavage sites. European journal of biochemistry, 202, 41-51.

LALLI, G., BOHNERT, S., DEINHARDT, K., VERASTEGUI, C. \& SCHIAVO, G. 2003. The journey of tetanus and botulinum neurotoxins in neurons. Trends in Microbiology, 11, 431-437.

LAURENCE, D. \& WEBSTER, R. 1963. Pathologic physiology, pharmacology, and therapeutics of tetanus. Clinical Pharmacology \& Therapeutics, 4, 36-72.

LAVINDER, J. J., WINE, Y., GIESECKE, C., IPPOLITO, G. C., HORTON, A. P., LUNGU, O. I., et al . 2014. Identification and characterization of the constituent human serum antibodies elicited by vaccination.Proceedings of the National Academy of Sciences of the United States of America, 111, 2259-2264.

LUKIĆ, I., MARINKOVIĆ, E., FILIPOVIĆ, A., KRNJAJA, O., KOSANOVIĆ, D., INIĆ-KANADA, A. \& STOJANOVIĆ, M. 2015. Key protection factors against tetanus: Anti-tetanus toxin antibody affinity and its ability to prevent tetanus toxin - ganglioside interaction. Toxicon, 103,135-144.

MASUYER, G., CONRAD, J. \& STENMARK, P. 2017. The structure of the tetanus toxin reveals pHmediated domain dynamics. EMBO reports,18, 1306-1317.

MASUYER, G., STANCOMBE, P., CHADDOCK, J. A. \& ACHARYA, K. R. 2011. Structures of engineered Clostridium botulinum neurotoxin derivatives. Acta Crystallographica Section F: Structural Biology 
and Crystallization Communications, 67, 1466-1472.

MAYER, S., LAUMER, M., MACKEnSEN, A., ANDREESEN, R. \& KRAUSE, S. W. 2002. Analysis of the immune response against tetanus toxoid: enumeration of specific $\mathrm{T}$ helper cells by the Elispot assay.Immunobiology, 205, 282-289.

MONHEIT, G. D. \& PICKETT, A. 2017. AbobotulinumtoxinA: a 25-year history. Aesthetic surgery journal, 37, S4-S11.

MOReno-IGOA, M., CAlvo, A. C., PEnAS, C., MAnzAno, R., Oliván, S., MUÑOZ, M. J., et al . 2010. Fragment $\mathrm{C}$ of tetanus toxin, more than a carrier. Novel perspectives in non-viral ALS gene therapy. Journal of Molecular Medicine, 88, 297-308.

NAUMANN, M., BOO, L. M., ACKERMAN, A. H. \& GALLAGHER, C. J. 2013. Immunogenicity of botulinum toxins. Journal of neural transmission, 120, 275-290.

OVESPIAN, S. V., BODEKER, M., O'LEARY, V. B., LAWRENCE, G. W. \& OLIVER DOLLY, J. 2015. Internalization and retrograde axonal trafficking of tetanus toxin in motor neurons and trans-synaptic propagation at central synapses exceed those of its C-terminal-binding fragments. Brain Structure and Function, $220,1825-1838$.

PAlERMO, A., WEBER, L. K., RENTSCHLER, S., ISSE, A., SEDLMAYR, M., HERBSTER, K., et al . 2017. Identification of a Tetanus Toxin Specific Epitope in Single Amino Acid Resolution. Biotechnology journal, 12, 1700197.

PATIL, S., WILlETT, O., THOMPKINS, T., HERMANN, R., RAMANATHAN, S., CORNETT, E. M., et al . 2016. Botulinum Toxin: Pharmacology and Therapeutic Roles in Pain States. Current Pain and Headache Reports, 20, 1-8.

PIRAZZINI, M., ROSSETTO, O., ElEOPRA, R. \& MONTECUCCO, C. 2017. Botulinum Neurotoxins: Biology, Pharmacology, and Toxicology.Pharmacological Reviews, 69, 200-235.

PIRAZZini, M., TEHRAN, D. A., LEKA, O., ZANETTI, G., ROSSETTO, O. \& MONTECUCCO, C. 2016. On the translocation of botulinum and tetanus neurotoxins across the membrane of acidic intracellular compartments.Biochimica et Biophysica Acta (BBA) - Biomembranes, 1858, 467-474.

POULAIN, B. \& POPOFF, M. R. 2019. Why are botulinum neurotoxin-producing bacteria so diverse and botulinum neurotoxins so toxic? Toxins, 11, 34 .

QAZI, O., SESARDIC, D., TIERNEY, R., SODERBACK, Z., CRANE, D., BOLGIANO, B. \& FAIRWEATHER, N. 2006. Reduction of the ganglioside binding activity of the tetanus toxin HC fragment destroys immunogenicity: implications for development of novel tetanus vaccines. Infect Immun, 74, 4884-91.

RESTANI, L., GIRIBALDI, F., MANICH, M., BERCSENYI, K., MENENDEZ, G., ROSSETTO, O., et al. 2012. Botulinum Neurotoxins A and E Undergo Retrograde Axonal Transport in Primary Motor Neurons. PLoS Pathogens, 8.

ROSSETTO, O., PIRAZZINI, M., BOlOGNESE, P., RIGONI, M. \& MONTECUCCO, C. 2011. An update on the mechanism of action of tetanus and botulinum neurotoxins. Acta Chimica Slovenica, 58, 702-707.

SASSE, A., CONDUIT, R., RYAN, D., WOODS, W. \& TUCKER, A. P. 2005. A pharmacotherapy for obstructive sleep apnea. Sleep, 28,1015-1016.

SEITHER, R., LORETAN, C., DRIVER, K., MellerSON, J. L., KNiGHTON, C. L. \& BLACK, C. L. 2019. Vaccination Coverage with Selected Vaccines and Exemption Rates Among Children in KindergartenUnited States, 2018-19 School Year. Morbidity and Mortality Weekly Report, 68,905.

SHAPIRA, A. \& BENHAR, I. 2010. Toxin-Based Therapeutic Approaches. Toxins, 2, 2519-2583. 
STUDIER, F. W. 2005. Protein production by auto-induction in high-density shaking cultures. Protein Expression and Purification, 41, 207-234.

SutTon, J. M., CHOW-WORn, O., SPAVEn, L., Silman, N. J., HALlis, B. \& SHONE, C. C. 2001. Tyrosine-1290 of tetanus neurotoxin plays a key role in its binding to gangliosides and functional binding to neurones.FEBS Letters, 493, 45-49.

TABAN, M. \& PERRY, J. D. 2006. Pearls of botox usage.Oculoplastic Surgery, 4, 165-169.

TURTON, K., CHADDOCK, J. A. \& ACHARYA, K. R. 2002. Botulinum and tetanus neurotoxins: structure, function and therapeutic utility. Trends in Biochemical Sciences, 27, 552-558.

UMland, S. P., NAhrebne, D. K., RAZAC, S., BEAVIS, A., PENnline, K. J., EGAN, R. W. \& BILLAH, M. M. 1997. The inhibitory effects of topically active glucocorticoids on IL-4, IL-5, and interferon$\gamma$ production by cultured primary CD4+ T cells. Journal of allergy and clinical immunology, 100, 511-519.

WANG, J., MENG, J., LAWRENCE, G. W., ZURAWSKI, T. H., SASSE, A., et al . 2008. Novel chimeras of botulinum neurotoxins $\mathrm{A}$ and $\mathrm{E}$ unveil contributions from the binding, translocation, and protease domains to their functional characteristics. Journal of Biological Chemistry, 283, 16993-17002.

WANG, J., ZURAWSKI, T. H., MENG, J., LAWRENCE, G. W., AOKI, K. R., WHEELER, L. \& DOLLY, J. O. 2012. Novel chimeras of botulinum and tetanus neurotoxins yield insights into their distinct sites of neuroparalysis. FASEB Journal, 26, 5035-5048.

WILSON, P., SlADE, R., CURRIE, B. J., WALTON, S. F., HOLT, D. C., FISCHER, K., et al . 2003. Mechanisms for a novel immune evasion strategy in the scabies mite Sarcoptes scabiei: a multigene family of inactivated serine proteases. Journal of investigative dermatology, 121, 1419-1424.

YOUSEFI, M., TAHMASEBI, F., YOUNESI, V., RAZAVI, A., KHOSHNOODI, J., BAYAT, A. A., et al . 2014. Characterization of neutralizing monoclonal antibodies directed against tetanus toxin fragment C. Journal of Immunotoxicology, 11, 28-34.

YOUSEFI, M., YOUNESI, V., BAYAT, A. A., JADIDI-NIARAGH, F., ABBASI, E., RAZAVI, A., et al . 2016. Comparative human and mouse antibody responses against tetanus toxin at clonal level. Journal of Immunotoxicology, 13, 243-248.
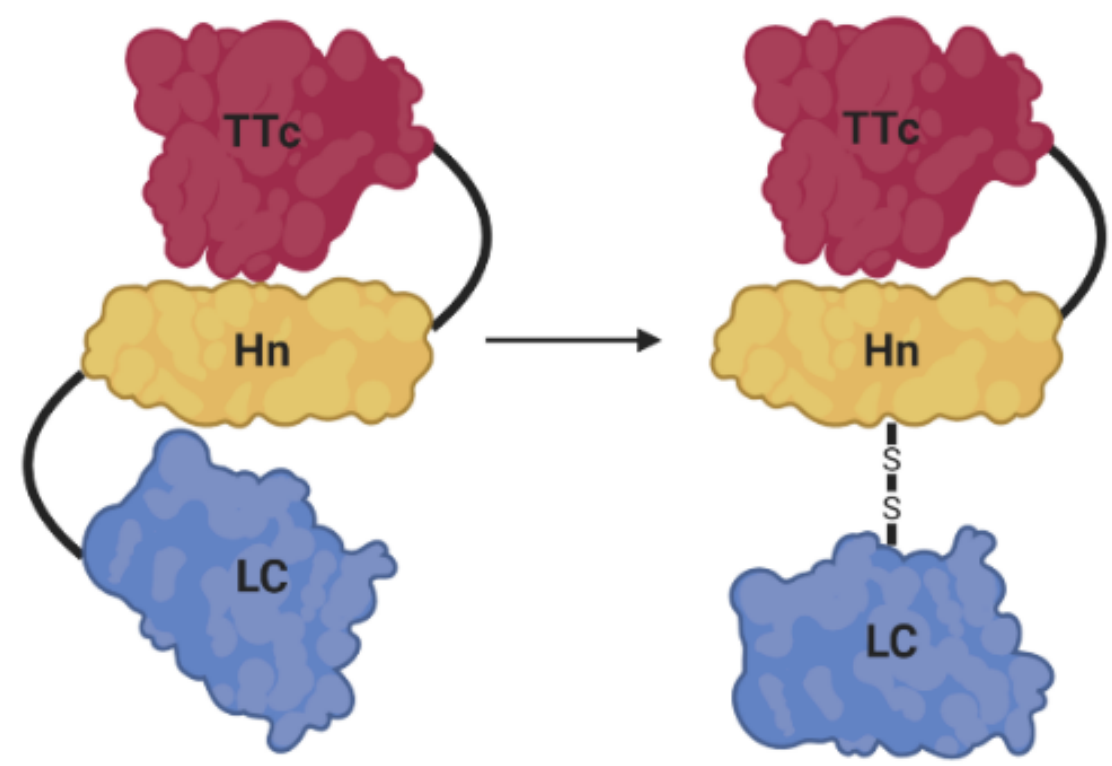

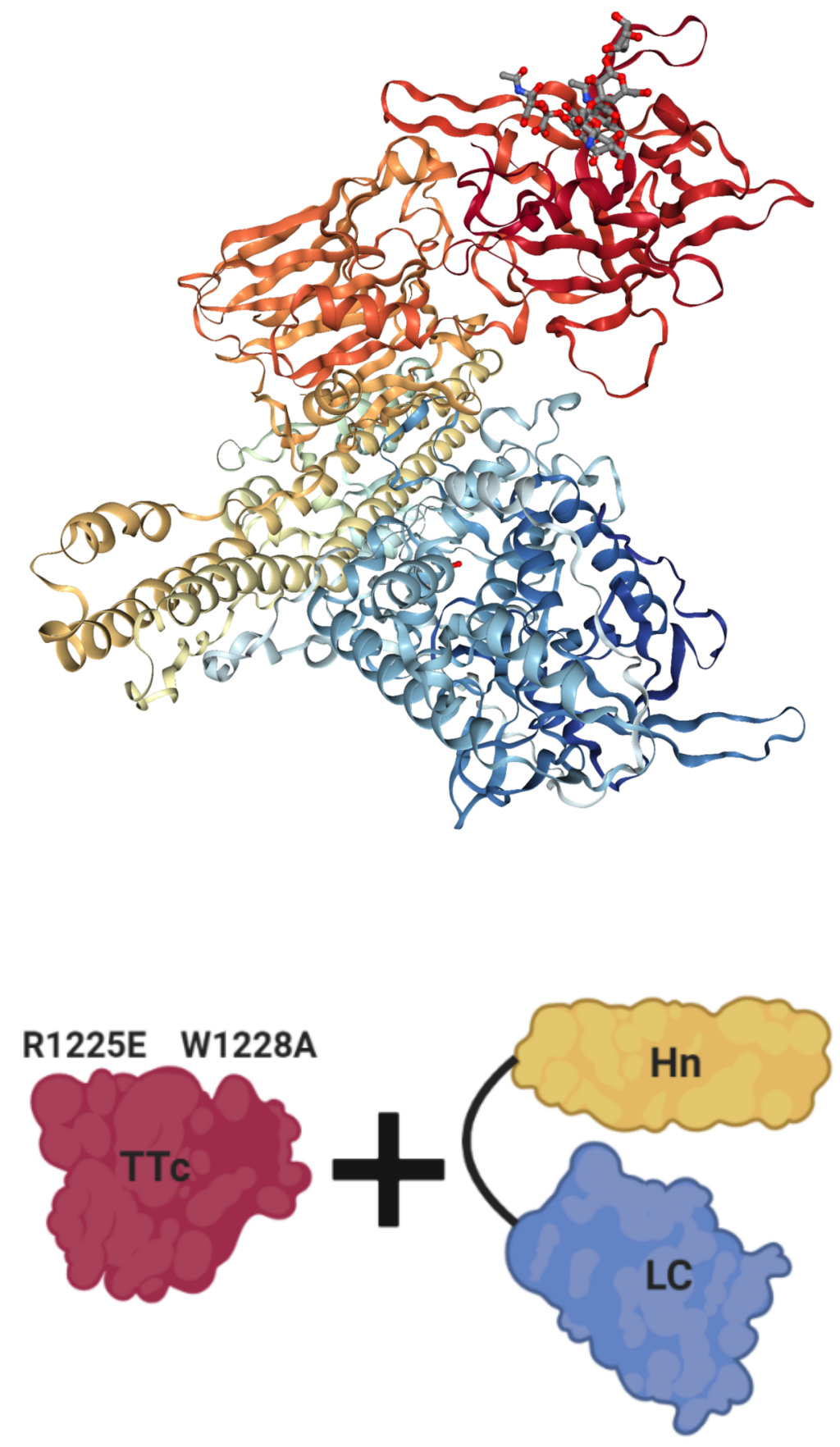

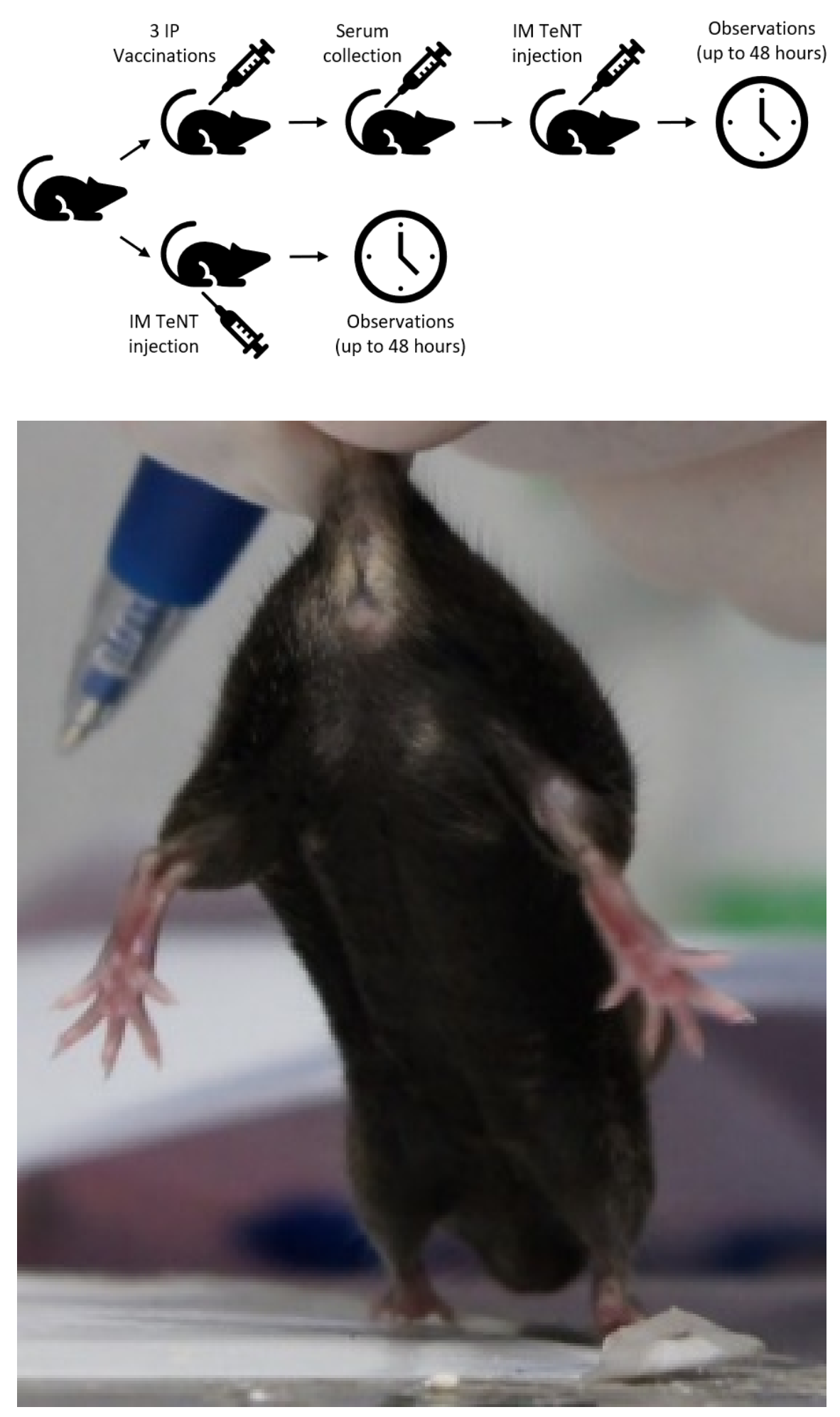

Figure 1. TeNT and decoy molecules and study outline. A) Representation of the structure of TeNT bound to a synthetic ganglioside GD1a analogue, derived from x-ray crystallography data (PDB 5N0B, Masuyer et. al. 2017 (Masuyer et al. , 2017)). TeNT is displayed as a ribbon model, with the TTc domain 
displayed in red and orange with the ganglioside GD1a receptor as a grey ball-and-stick model. The TeNT Hn domain is displayed in yellow and the LC domain is displayed in blue. B) Diagrammatic representation of the activation of TeNT from expressed form to di-chain form. C) The two inactive recombinant protein components of the decoy solution, TTc fragment with mutated ganglioside binding regions and LCHn. D)Schematic representations of the trial procedure. The vaccinated mouse procedure is on top and the naïve mouse procedure beneath. E)Example observations of tetany in trial animals demonstrated stage 0-4 tetany from left to right. Stage 0-2 is difficult to differentiate from still images and are generally observed during animal movement.

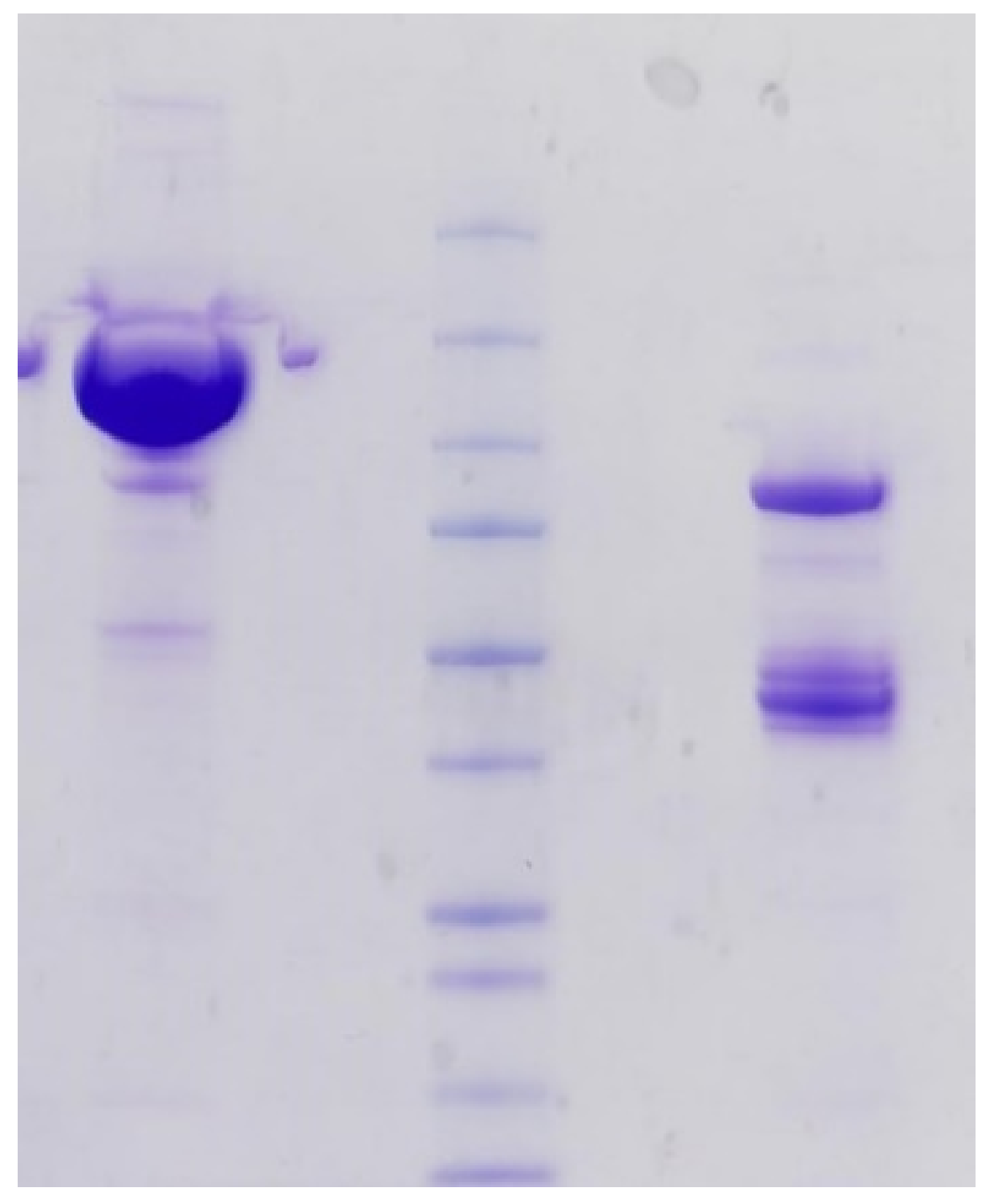




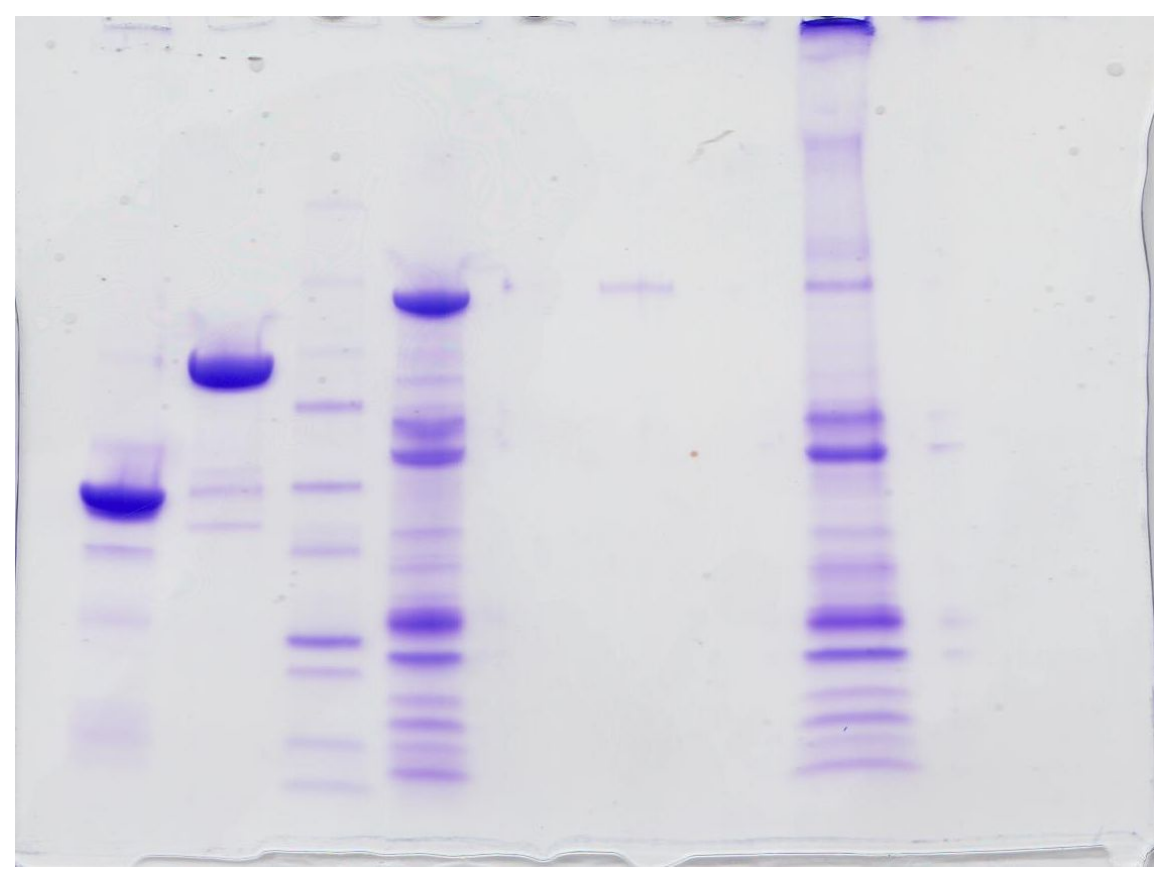




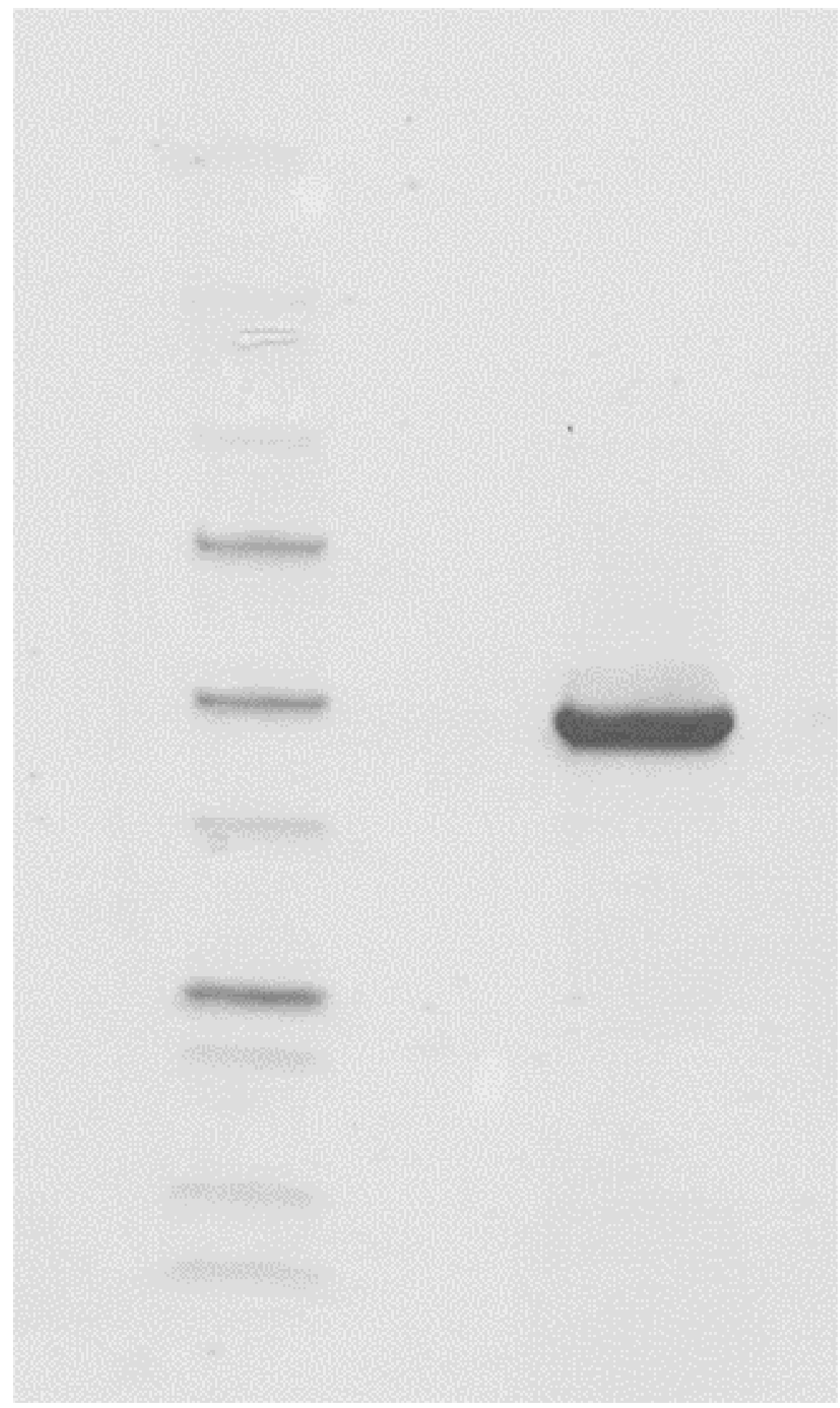

Figure 2. Expression and purification of recombinant TeNT and inactivated decoy molecules . A) SDS-PAGE and Western Blot of purified recombinant TeNT (lanes 1 and 2) and activated di-chain TeNT when non-reduced (lane 3) compared to reduced (lane 4). TeNT was detected at $150 \mathrm{kDa}$, and activated, reduced TeNT demonstrated the expected $100 \mathrm{kDa}$ heavy-chain and $50 \mathrm{kDa}$ light-chain domains. B)SDS- 
PAGE and Western blot of TTc R1225E, W1288A (lanes 1 and 2). TTc was detected at $50 \mathrm{kDa}$ as expected. C) SDS-PAGE and Western blot of LCHn (lanes 1 and 2). LCHn was detected at $100 \mathrm{kDa}$ as expected, comprising of the $50 \mathrm{kDa}$ light-chain and $\mathrm{Hn}$ regions.
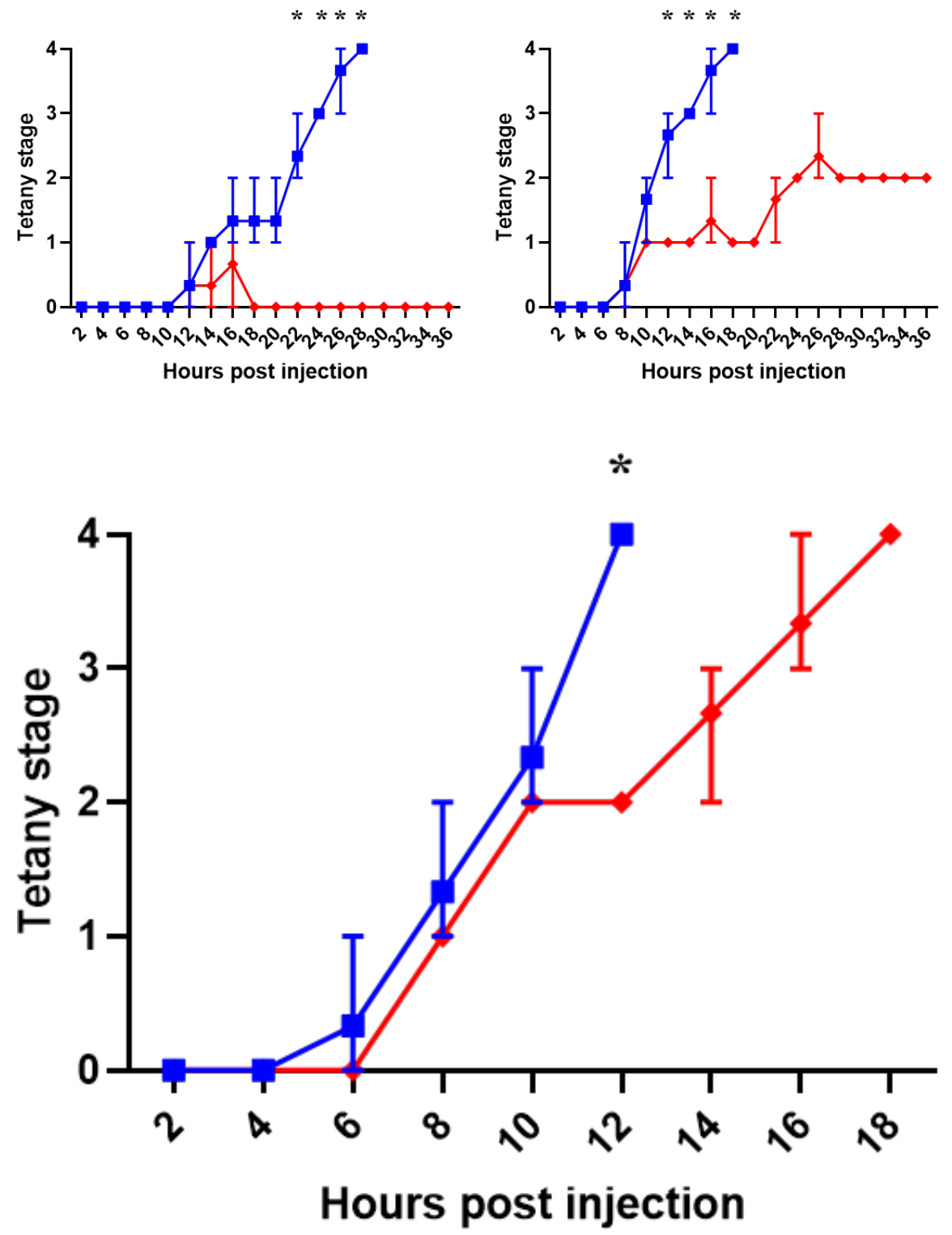

Figure 3. Activity of TeNT and TeNT + Decoy molecules in naïve mice. A) Time course of tetany stage induced by $0.01 \mathrm{ng}$ of TeNT (Blue) compared to $0.01 \mathrm{ng}$ TeNT with $100 \mu \mathrm{g}$ of equimolar decoy solution (Red).B) Time course of tetany stage induced by $0.1 \mathrm{ng}$ of TeNT (Blue) and $0.1 \mathrm{ng}$ TeNT with $100 \mu \mathrm{g}$ of equimolar decoy solution (Red).C) Time course of tetany stage induced by $1 \mathrm{ng}$ of TeNT (Blue) and $1 \mathrm{ng}$ TeNT with $100 \mu \mathrm{g}$ of equimolar decoy solution (Red). Multiple t-test analyses were performed and statistical significance determined using the Holm-Sidak method, with alpha $=0.05$. Each time point was analysed individually, without assuming a consistent SD. An asterisk denotes a time point with statistical significance $(\mathrm{p}<0.05)$. The error bars show the range of tetany stages observed at each time point and where no error bar is displayed, all animals displayed the same stage of tetanus. 

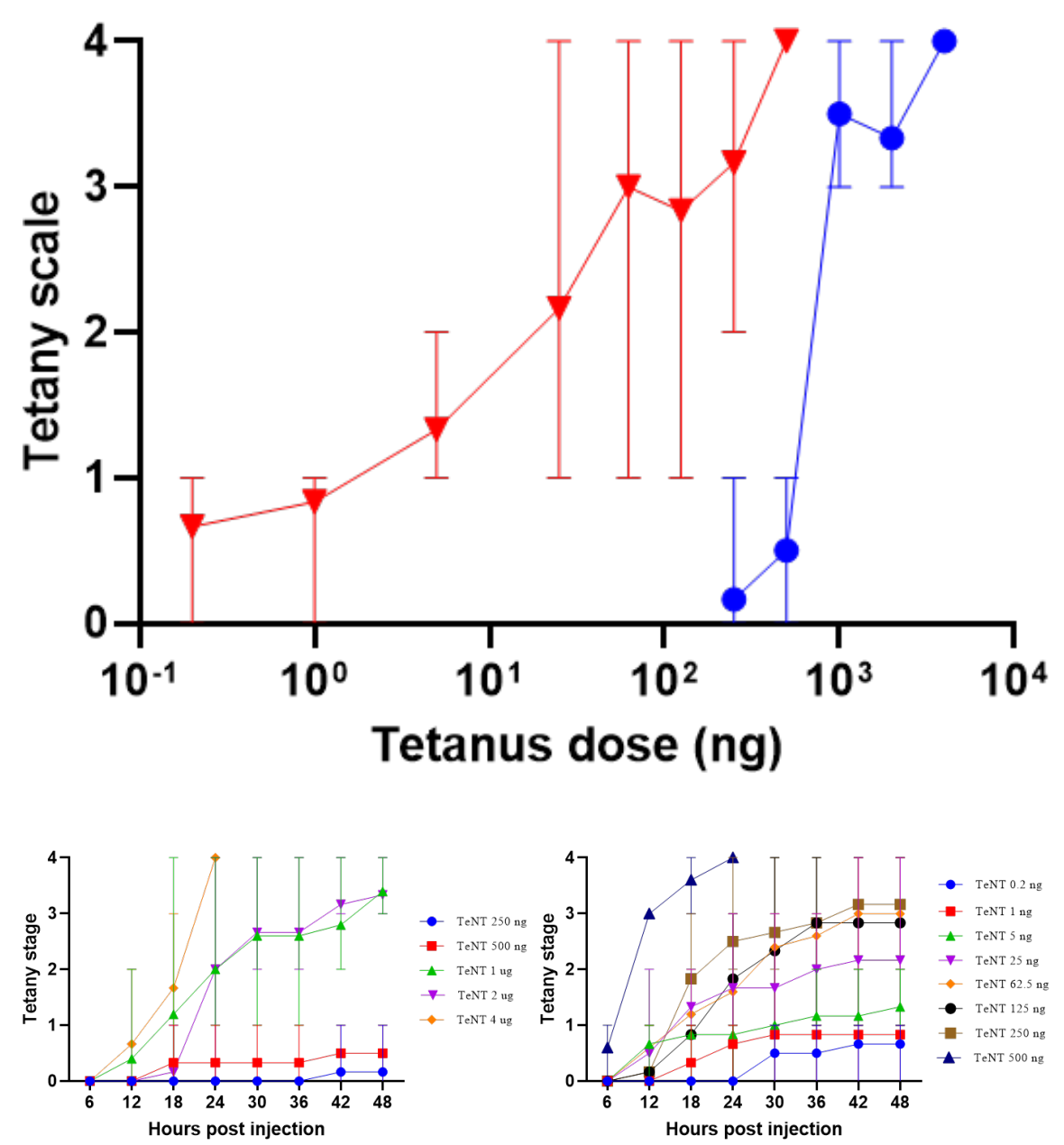

\section{Hosted file}

image27.emf available at https://authorea.com/users/321772/articles/450958-inactivatedtetanus-as-an-immunological-smokescreen-a-major-step-towards-harnessing-tetanus-basedtherapeutics

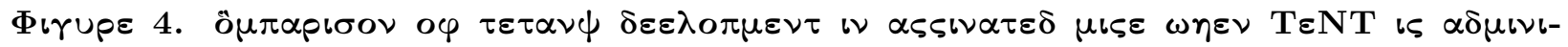

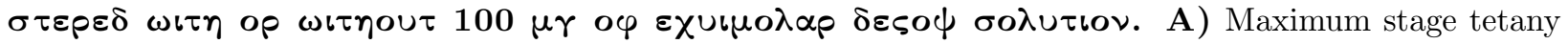
reached in 48 hours by TeNT dose. Blue circle is dosage with TeNT and red triangle is dosage with TeNT and $100 \mu \mathrm{g}$ decoy solution. B) Time course of tetany development for all doses of TeNT alone. C) Time course of tetany development for all doses of TeNT with $100 \mu \mathrm{g}$ decoy solution. D) Comparison of time course of tetany development of TeNT $500 \mathrm{ng}$ (blue) and TeNT $500 \mathrm{ng}$ decoy $100 \mu \mathrm{g}$ (red). E) Comparison of time course of tetany development of TeNT $250 \mathrm{ng}$ (blue) and TeNT $250 \mathrm{ng}$ decoy $100 \mu \mathrm{g}$ (red). Multiple t-test analyses were performed and statistical significance determined using the Holm-Sidak method, with alpha $=0.05$. Each time point was analysed individually, without assuming a consistent SD. An asterisk denotes a time point with statistical significance $(\mathrm{p}<0.05)$. The error bars show the range of tetany stages observed at each time point and where no error bar is displayed, all animals displayed the same stage of tetany. 

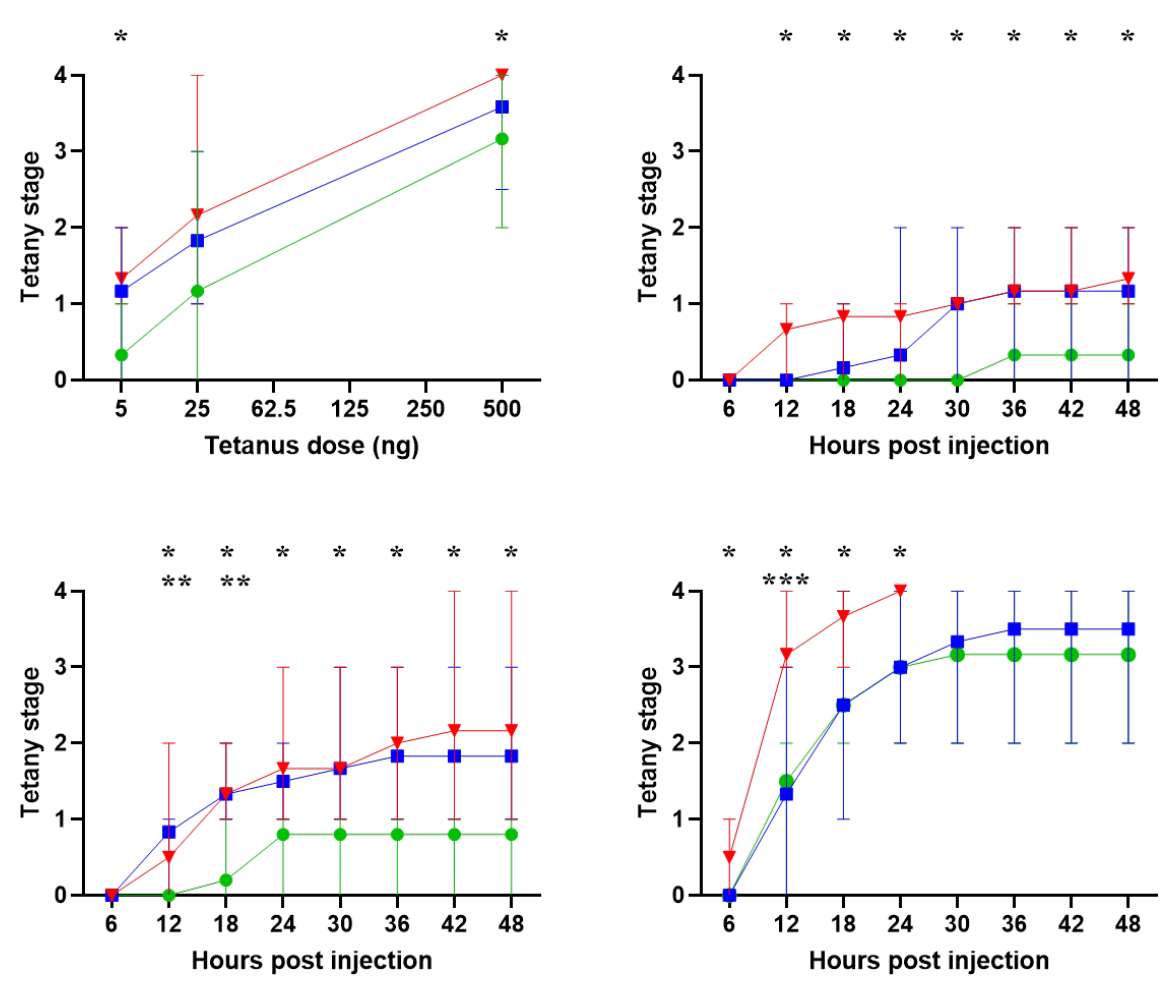

Figure 5. Comparison of tetany development in vaccinated mice when TeNT is administered with different concentrations of decoy solution. A) Comparison of maximum tetany stage reached in 48 hours at different toxin doses with $100 \mu \mathrm{g}$ of equimolar decoy solution (red triangle), $20 \mu \mathrm{g}$ of equimolar decoy solution (blue square) and $5 \mu \mathrm{g}$ of equimolar decoy solution (green circle). B) Comparison of time course of tetany symptoms for mice administered $5 \mathrm{ng}$ of TeNT with $100 \mu \mathrm{g}$ of equimolar decoy solution (red triangle), $20 \mu \mathrm{g}$ of equimolar decoy solution (blue square) and $5 \mu \mathrm{g}$ of equimolar decoy solution (green circle). C) Comparison of time course of tetany symptoms for mice administered $25 \mathrm{ng}$ of TeNT with $100 \mu \mathrm{g}$ of equimolar decoy solution (red triangle), $20 \mu \mathrm{g}$ of equimolar decoy solution (blue square) and $5 \mu \mathrm{g}$ of equimolar decoy solution (green circle). D) Comparison of time course of tetany symptoms for mice administered 500 ng of TeNT with $100 \mu \mathrm{g}$ of equimolar decoy solution (red triangle), $20 \mu \mathrm{g}$ of equimolar decoy solution (blue square) and $5 \mu \mathrm{g}$ of equimolar decoy solution (green circle). Multiple t-test analyses were performed and statistical significance determined using the Holm-Sidak method, with alpha $=0.05$. Each dose $(\mathbf{A})$ or time-point (B-D ) was analysed individually, without assuming a consistent SD. For A , an asterisk denotes a dose point with statistical significance $(\mathrm{p}<0.05)$ between $100 \mu \mathrm{g}$ and $5 \mu \mathrm{g}$ of equimolar decoy solution. For B-D , a single asterisk denotes $\mathrm{p}<0.05$ between $100 \mu \mathrm{g}$ and $5 \mu \mathrm{g}$ of decoy, a double asterisk denotes $\mathrm{p}$ $<0.05$ between $20 \mu \mathrm{g}$ and $5 \mu \mathrm{g}$ of decoy and a triple asterisk denotes $\mathrm{p}<0.05$ between $100 \mu \mathrm{g}$ and $20 \mu \mathrm{g}$ of decoy. The error bars show the range of tetany stages observed at each time point and where no error bar is displayed, all animals displayed the same stage of tetany.

\section{Supplementary data}

Table 1. Anti-TeNT antibody titre for each mouse included in the trial ${ }^{*}$ denotes mice that were excluded

\section{Group}

TeNT $250 \mathrm{ng}$

TeNT $500 \mathrm{ng}$

TENT $1 \mu \gamma$ 
Table 1. Anti-TeNT antibody titre for each mouse included in the trial ${ }^{*}$ denotes mice that were excluded

TeNT $2 \mu \gamma$

TENT $4 \mu \gamma$

TENT $0.2 \nu \gamma \Delta \varepsilon \varsigma \circ \psi 100 \mu \gamma$

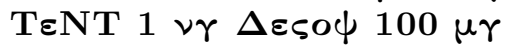

TeNT $5 \nu \gamma \Delta \varepsilon \varsigma 0 \psi 100 \mu \gamma$

TeNT $25 \nu \gamma \Delta \varepsilon \varsigma 0 \psi 100 \mu \gamma$

TeNT $62.5 \nu \gamma \Delta \varepsilon \varsigma 0 \psi 100 \mu \gamma$

TENT $125 \nu \gamma \Delta \varepsilon \varsigma \circ \psi 100 \mu \gamma$

TeNT $250 \nu \gamma \Delta \varepsilon \varsigma 0 \psi 100 \mu \gamma$

TENT $500 \nu \gamma \Delta \varepsilon \varsigma 0 \psi 100 \mu \gamma$

TeNT $5 \nu \gamma \Delta \varepsilon \varsigma 0 \psi 20 \mu \gamma$

TeNT $25 \nu \gamma \Delta \varepsilon \varsigma 0 \psi 20 \mu \gamma$

TeNT $500 \nu \gamma \Delta \varepsilon \varsigma 0 \psi 20 \mu \gamma$

TENT $5 \nu \gamma \Delta \varepsilon \varsigma \circ \psi 5 \mu \gamma$

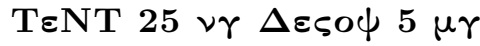

TeNT $500 \nu \gamma \Delta \varepsilon \varsigma 0 \psi 5 \mu \gamma$ 